\title{
Structures of Cu-Based Glass Forming System Doped with Iron
}

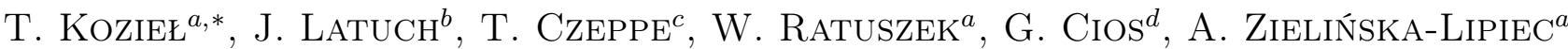 \\ AND P. BAŁA ${ }^{a, d}$ \\ ${ }^{a}$ Faculty of Metals Engineering and Industrial Computer Science, AGH University of Science and Technology, \\ al. A. Mickiewicza 30, 30-059 Krakow, Poland \\ ${ }^{b}$ Faculty of Materials Science and Engineering, Warsaw University of Technology, \\ Wołoska 141, 02-507 Warsaw, Poland \\ ${ }^{c}$ Institute of Metallurgy and Materials Sciences, Polish Academy of Sciences, \\ W. Reymonta 25, 30-059 Krakow, Poland \\ ${ }^{d}$ Academic Centre for Materials and Nanotechnology, AGH University of Science and Technology, \\ al. A. Mickiewicza 30, 30-059 Krakow, Poland
}

The effects of iron additions on the structure of $\left(\mathrm{Cu}_{0.47} \mathrm{Ti}_{0.34} \mathrm{Zr}_{0.11} \mathrm{Ni}_{0.08}\right)_{100-x} \mathrm{Fe}_{x}(x=0,1.5,3,6)$ glass forming system are presented. The alloys were synthesized by arc melting of high purity elements and melt spun to form rapidly quenched ribbons. X-ray diffraction studies showed the amorphous structure of the base and Fe-containing alloys, confirmed by the presence of exothermic peaks on differential scanning calorimetry curves. Bulk samples in the form of rods $(\Phi 3 \times 55 \mathrm{~mm})$ were cast using a suction casting unit attached to the arc melter. Structural investigations revealed partial crystallization of the base $\mathrm{Cu}_{47} \mathrm{Ti}_{34} \mathrm{Zr}_{11} \mathrm{Ni}_{8}$ alloy. Iron additions significantly decreased the glass forming ability of the alloy, leading to primary crystallization of dendrites.

DOI: 10.12693/APhysPolA.130.913

PACS/topics: 81.05.Kf, 81.05.Bx, 61.05.cp, 68.37.Hk

\section{Introduction}

Metallic glasses exhibit superior physical and mechanical properties compared to their crystalline counterparts. These materials have attracted a worldwide attention over the past decades, leading to a significant increase of a critical casting size from a micrometre to a centimetre level [1]. In order to increase the glass forming ability (GFA) of an alloy, its composition must satisfy the three empirical rules given by Inoue: (1) at least three alloying elements, (2) large mismatch in atomic sizes, and (3) large negative heat of mixing among constituent elements [2]. Bulk metallic glasses (BMGs) with each size of minimum $1 \mathrm{~mm}$ have been synthesised in many ferrous and non-ferrous systems which satisfy the above mentioned rules [1,3-6]. Among BMGs, Cu-based systems are very attractive for engineering applications due to a high glass forming ability and a high strength at a relatively low cost of constituent elements compared to other glass forming systems [7-9].

A main drawback of monolithic BMGs, including $\mathrm{Cu}-$ based systems, is a lack of global plasticity, which limits their potential applications. It is expected that amorphous-crystalline composites, consisting of a ductile crystalline phase embedded in an amorphous matrix, should exhibit increased ductility. Such composites can be obtained by in situ formation of a crystalline phase during cooling of the melt. One approach is to use a liquid phase separation phenomenon existing in alloys

\footnotetext{
* corresponding author; e-mail: tkoziel@agh.edu.pl
}

containing at least one pair of elements that exhibit a positive heat of mixing. By proper alloying, it is possible to increase the glass forming abilities of both melts, and a two-phase metallic glass can be formed upon cooling [10-12]. If a GFA of one melt will be not sufficient, amorphous-crystalline composites, containing sphericalshape crystalline precipitates embedded in an amorphous matrix, can be obtained [13-16]. However, a thermodynamic condition for liquid phase separation is in contrast with Inoue's empirical rule, which in turn significantly decreases the overall GFA of alloy. Thus formation of twophase metallic glasses or amorphous-crystalline composites in liquid immiscible systems requires using casting methods with very high cooling rates (i.e. melt spinning, splat quenching).

This work shows the effect of an iron addition on the structure and properties of the $\mathrm{Cu}-\mathrm{Ti}-\mathrm{Zr}-\mathrm{Ni}$ glass forming system. The base (Fe-free) system generally satisfies Inoue's empirical rules (except the $\mathrm{Cu}-\mathrm{Ni}$ pair exhibiting positive heat of mixing). On the other hand, Fe exhibits positive heat of mixing with $\mathrm{Cu}(+13 \mathrm{~kJ} / \mathrm{mol})$ [17]. Two casting methods with different cooling rates, melt spinning and suction casting, were used in order to investigate an iron addition to the $\mathrm{Cu}$-base glass forming system.

\section{Experimental details}

Alloy specimens of nominal composition $\left(\mathrm{Cu}_{0.47} \mathrm{Ti}_{0.34} \mathrm{Zr}_{0.11} \mathrm{Ni}_{0.08}\right)_{100-x} \mathrm{Fe}_{x}(x=0,1.5,3,6)$ were synthesised by arc melting of elements (purity $\geq 99.9 \%$ ) in a Ti-gettered argon atmosphere. Before melting, the chamber was first evacuated to $<5 \times 10^{-2}$ mbar, backfilled with high purity $(6 \mathrm{~N})$ argon and re-evacuated. 
The backfill-evacuation cycle was performed three times to minimize the oxygen level in the chamber. After the third evacuation, the chamber was evacuated to $<5 \times 10^{-5}$ mbar by using a turbomolecular pump. Pieces of elemental components (total mass $6 \mathrm{~g}$ ) were arc melted at a partial pressure of Ar and solidified on a water-cooled $\mathrm{Cu}$ hearth. Each sample was melted four times to ensure its homogenisation.

Rapidly solidified alloys were prepared by the melt spinning technique (Edmund Bühler melt spinner HV) at a linear wheel speed of $35 \mathrm{~m} / \mathrm{s}$ and a protective gas (argon) over-pressure of $20 \mathrm{kPa}$. Bulk cylindrical samples, with diameters of $3 \mathrm{~mm}$ and lengths of $55 \mathrm{~mm}$, were prepared using a special water-cooled suction casting unit. A minimum axial cooling rate was estimated to be about $200 \mathrm{~K} / \mathrm{s}$ [18].

Melt-spun ribbons and suction-cast rods were submitted to X-ray diffraction (XRD) studies using a $\mathrm{Cu} K_{\alpha}$ radiation (Siemens D500). In the case of rods, the analysis was performed on the ground cross-sections of rods. Differential scanning calorimetry (DSC) at a constant heating rate of $20 \mathrm{~K} / \mathrm{min}$ was used to study the crystallization behaviour (TA Instruments Q600). Microstructural observations of bulk samples were carried out on polished cross-sections of rods (final polishing with colloidal silica suspension) using optical microscopy and scanning electron microscopy (FEI Nova NanoSEM 450).

\section{Results and discussion}

XRD patterns of the melt-spun and suction-cast $\left(\mathrm{Cu}_{0.47} \mathrm{Ti}_{0.34} \mathrm{Zr}_{0.11} \mathrm{Ni}_{0.08}\right)_{100-x} \mathrm{Fe}_{x}(x=0,1.5,3,6)$ alloys are shown in Fig. 1. In the case of the rapidly cooled melt-spun ribbons (Fig. 1a), only broad diffraction maxima, without any detectable Bragg peaks, were recorded for all compositions. Similar halo, indicating amorphous structure of the alloy, was observed for the bulk suctioncast base (iron free) alloy (Fig. 1b). On the other hand, crystalline phases were detected in the case of alloy rods doped with $\mathrm{Fe}(x=1.5,3,6)$. For the lowest Fe content, only two cubic phases, $\mathrm{Cu} 0.8 \mathrm{Fe} 0.2 \mathrm{Ti}$ and $\mathrm{CuNiTi}$, were identified, indicating a possible fraction of an amorphous phase. Two additional phases, hexagonal Cu51Zr14 and tetragonal $\mathrm{CuTi}$, were identified in alloys with $\mathrm{Fe}$ contents $x=3 \%$ and $6 \%$.

Figure 2 shows DSC curves of the melt-spun (Fig. 2a) and suction-cast (Fig. 2b) alloys, recorded at a constant heating rate of $20 \mathrm{~K} / \mathrm{min}$. Multiple-stage crystallization was noticed for the base composition $(x=0)$ alloy. Moreover, despite similar onset crystallization temperatures of the first peaks $\left(449-450^{\circ} \mathrm{C}\right)$, a higher glass transition temperature was noticed for the suction-cast rod. On the other hand, the crystallization behaviour significantly changed with $\mathrm{Fe}$ presence. Increase of $\mathrm{Fe}$ content in the melt-spun ribbons, not only shifted onset crystallization temperatures to higher values, but also decreased total enthalpies of crystallization (Fig. 2a). More pronounced effect of $\mathrm{Fe}$ on the glass-forming ability was noticed for bulk samples. No glass transition temperature could be

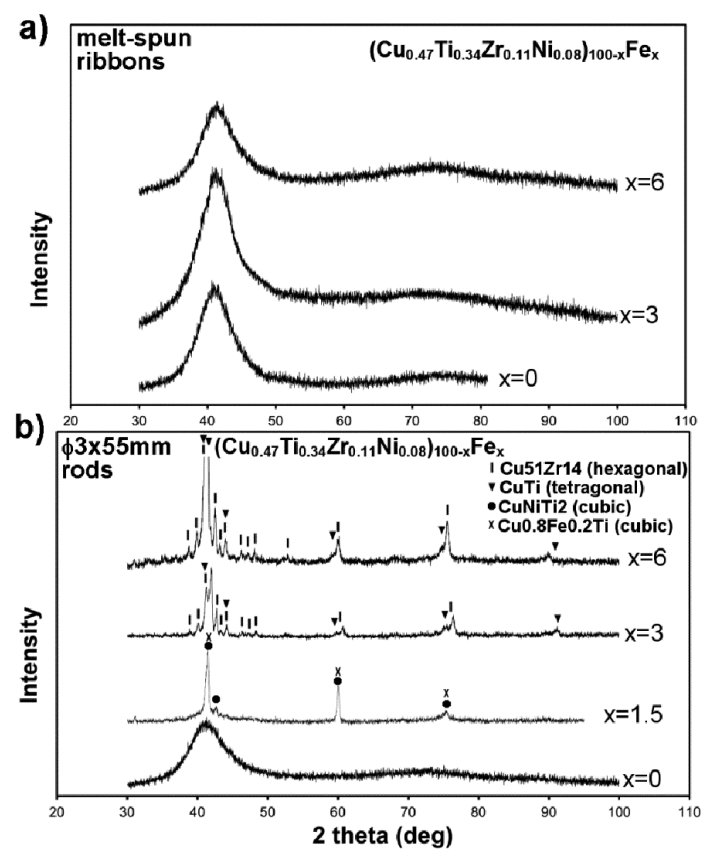

Fig. 1. XRD patterns of the a) melt-spun ribbons and b) suction-cast $3 \mathrm{~mm}$ diameter rods.

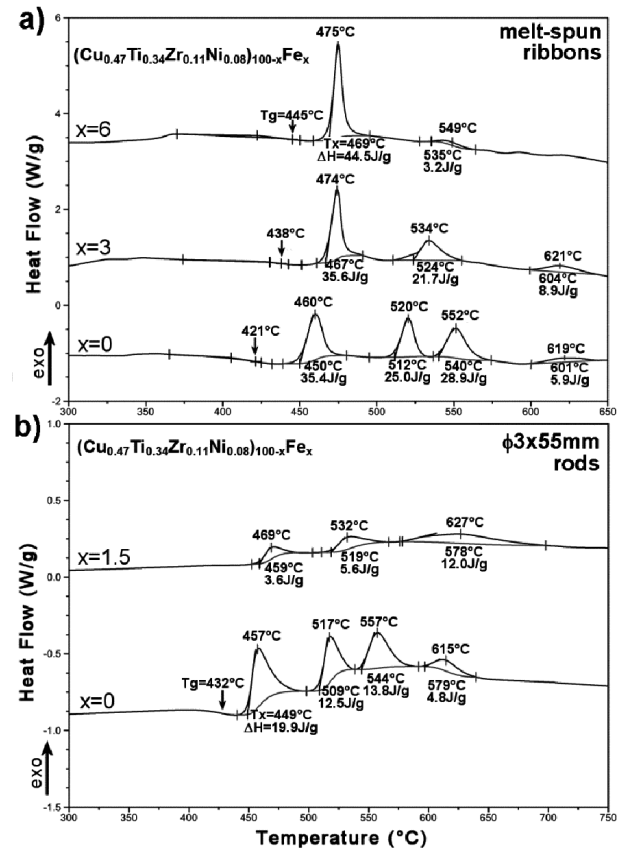

Fig. 2. DSC curves of the a) melt-spun ribbons and b) suction-cast $3 \mathrm{~mm}$ diameter rods (heating rate of 20 $\mathrm{K} / \mathrm{min})$.

detected on the DSC curve for the alloy containing only $1.5 \%$ Fe (Fig. 2b).

Microstructures of the as-cast rods are presented in Figs. 3 and 4. Low magnification observations enabled us to reveal partial crystallization of the base alloy (Fig. 3a) and traces of the amorphous phase in the alloy doped with $x=1.5 \%$ Fe (Fig. 3b). Presence of amorphous phase 


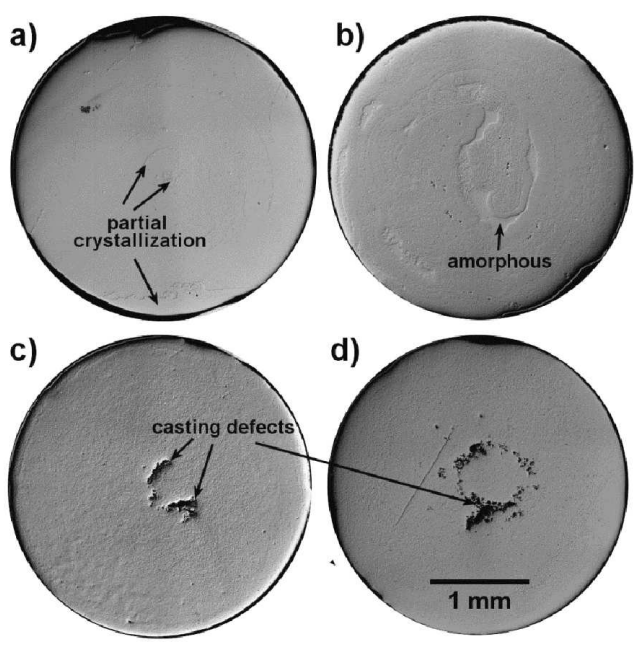

Fig. 3. Optical micrographs of as-cast $\left(\mathrm{Cu}_{0.47} \mathrm{Ti}_{0.34} \mathrm{Zr}_{0.11} \mathrm{Ni}_{0.08}\right)_{100-x} \mathrm{Fe}_{x}$ alloy rods: a) $x=0$, b) $x=1.5$, c) $x=3$ and d) $x=6$.

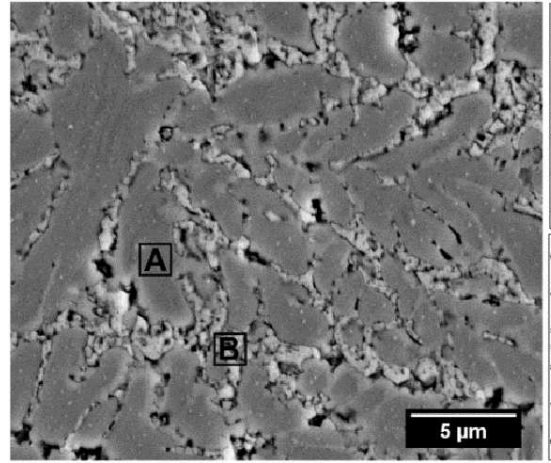

Fig. 4. SEM

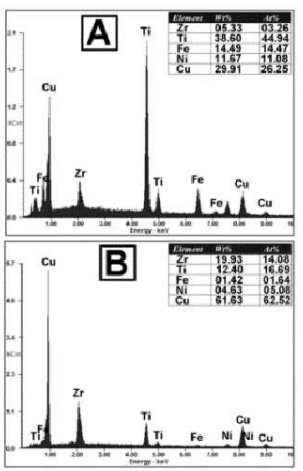

of

as-cast
$\left(\mathrm{Cu}_{0.47} \mathrm{Ti}_{0.34} \mathrm{Zr}_{0.11} \mathrm{Ni}_{0.08}\right)_{94} \mathrm{Fe}_{6}$ alloy with corresponding EDS spectra of denritic (A) and interdendritic (B) regions.

in the alloy containing $1.5 \% \mathrm{Fe}$ was confirmed by small exothermic effect on the DSC curve (Fig. 2b). No evidence of amorphous phase was noticed in the case of alloys containing $x=3$ and $6 \% \mathrm{Fe}$, but typical casting defects could be observed (Fig. 3c,d). More detailed microstructural observations of the alloy containing $6 \% \mathrm{Fe}$ (Fig. 4) showed well-developed dendrites enriched with $\mathrm{Ti}, \mathrm{Fe}$, and Ni. The chemical composition of the interdendritic regions, which are enriched with $\mathrm{Cu}$ and $\mathrm{Zr}$, corresponds to the $\mathrm{Cu} 51 \mathrm{Zr} 14$ phase.

The addition of $\mathrm{Fe}$ to the $\mathrm{Cu}$-based system shifted chemical composition out of the glass-forming range and brought about dendritic solidification of alloys. Despite positive heat of mixing between $\mathrm{Cu}$ and $\mathrm{Fe}$, no evidence of liquid phase separation was noticed, even for a highest Fe content.

\section{Conclusions}

Based on the presented results the following conclusions can be drawn:
1. Rapid quenching (melt spinning process) of the $\left(\mathrm{Cu}_{0.47} \mathrm{Ti}_{0.34} \mathrm{Zr}_{0.11} \mathrm{Ni}_{0.08}\right)_{100-x} \mathrm{Fe}_{x}$ alloys produced an amorphous structure of the base $(x=0)$ and Fe-doped ( $x=3$ and 6 ) alloys.

2. XRD studies showed a fully amorphous structure of the base suction-cast alloy, but microstructural observations revealed its partial crystallization.

3. Doping with Fe significantly deteriorated the glass forming ability of this alloy, leading to dendritic crystallization during the suction casting process.

4. No evidence of liquid phase separation was noticed.

\section{Acknowledgments}

This work was supported by the Polish National Science Centre (NCN) under contract No. 2011/03/D/ST8/04131.

\section{References}

[1] A. Inoue, A. Takeuchi, Acta Mater. 59, 2243 (2011).

[2] A. Inoue, Acta Mater. 48, 279 (2000).

[3] V. Ponnambalam, S.J. Poon, G.J. Shiflet, V.M. Keppens, R. Taylor, G. Petculescu, Appl. Phys. Lett. 83, 1131 (2003)

[4] J. Latuch, P. Krzesniak, T. Kulik, J. Alloys Comp. 483, 47 (2009).

[5] H. Tan, Y. Zhang, Y. Li, 0.1016/S09669795(02)00148-6J. Appl. Phys. 10, 1203 (2002).

[6] R. Babilas, K. Cesarz-Andraczke, R. Nowosielski, A. Burian, J. Mater. Eng. Perform. 23, 2241 (2014).

[7] D. Xu, G. Duan, W.L. Johnson, Phys. Rev. Lett. 92, 245504 (2004).

[8] C.L. Dai, H. Guo, Y. Shen, Y. Li, E. Ma, J. Xu, Scr. Mater. 54, 1403 (2006).

[9] W. Zhang, Q. Zhang, C. Qin, A. Inoue, Mater. Sci. Eng. B 148, 92 (2008).

[10] A.A. Kündig, M. Ohnuma, D.H. Ping, T. Ohkubo, K. Hono, Acta Mater. 52, 2441 (2004).

[11] N. Mattern, T. Gemming, G. Goerigk, J. Eckert, Scr. Mater. 57, 29 (2007).

[12] B.J. Park, H.J. Chang, D.H. Kim, W.T. Kim, Appl. Phys. Lett. 85, 6353 (2004).

[13] K. Ziewiec, K. Bryła, A. Błachowski, K. Ruebenbauer, K. Prusik, S. Kąc, T. Kozieł, J. Microsc. 237, 232 (2010).

[14] K. Ziewiec, P. Malczewski, R. Gajerski, A. Ziewiec, J. Non. Cryst. Solids 357, 73 (2011).

[15] T. Kozieł, Z. Kędzierski, A. Zielińska-Lipiec, J. Latuch, G. Cieślak, J. Microsc. 237, 267 (2010).

[16] T. Kozieł, J. Latuch, A. Zielińska-Lipiec, Arch. Metall. Mater. 58, 601 (2013).

[17] A. Takeuchi, A. Inoue, Mater. Trans. 46, 2817 (2005).

[18] T. Kozieł, Arch. Metall. Mater. 60, 767 (2015). 